\title{
Knowledge of heart attack and stroke symptomology: a cross-sectional comparison of rural and non-rural US adults
}

\author{
Michael T Swanoski ${ }^{1}$, May Nawal Lutfiyya ${ }^{2 *}$, Maria L Amaro ${ }^{1}$, Michael F Akers ${ }^{1}$ and Krista L Huot ${ }^{3}$
}

\begin{abstract}
Background: Understanding the signs and symptoms of heart attacks and strokes are important not only in saving lives, but also in preserving quality of life. Findings from recent research have yielded that the prevalence of cardiovascular disease risk factors are higher in rural populations, suggesting that adults living in rural locales may be at higher risk for heart attack and/or stroke. Knowledge of heart attack and stroke symptomology as well as calling 911 for a suspected heart attack or stroke are essential first steps in seeking care. This study sought to examine the knowledge of heart attack and stroke symptoms among rural adults in comparison to non-rural adults living in the U.S.

Methods: Using multivariate techniques, a cross-sectional analysis of an amalgamated multi-year Behavioral Risk Factor Surveillance Survey (BRFSS) database was performed. The dependent variable for this analysis was low heart attack and stroke knowledge score. The covariates for the analysis were: age, sex, race/ethnicity, annual household income, attained education, health insurance status, having a health care provider (HCP), timing of last routine medical checkup, medical care deferment because of cost, self-defined health status and geographic locale.

Results: The weighted $\mathrm{n}$ for this study overall was 103,262,115 U.S. adults $>=18$ years of age. Approximately $22.0 \%$ of these respondents were U.S. adults living in rural locales. Logistic regression analysis revealed that those U.S. adults who had low composite heart attack and stroke knowledge scores were more likely to be rural $(\mathrm{OR}=1.21895 \% \mathrm{Cl} 1.216-1.219)$ rather than non-rural residents. Furthermore, those with low scores were more likely to be: male $(\mathrm{OR}=1.35395 \% \mathrm{Cl} 1.352-$ 1.354), $>65$ years of age $(\mathrm{OR}=1.36995 \% \mathrm{Cl} 1.368-1.371)$, African American $(\mathrm{OR}=1.892 \mathrm{95 \%} \% \mathrm{Cl} 1.889-1.894)$, not educated beyond high school $(\mathrm{OR}=1.400955 \mathrm{Cl} 1.399-1.402)$, uninsured $(\mathrm{OR}=1.30895 \% \mathrm{Cl} 1.3-6-1.310)$, without a $\mathrm{HCP}(\mathrm{OR}=1.216$ $95 \% \mathrm{Cl} 1.215-1.218)$, and living in a household with an annual income of $<\$ 50,000(\mathrm{OR}=1.42995 \% \mathrm{Cl} 1.428-1.431)$.

Conclusions: Analysis identified clear disparities between the knowledge levels U.S. adults have regarding heart attack and stroke symptoms. These disparities should guide educational endeavors focusing on improving knowledge of heart attack and stroke symptoms.
\end{abstract}

Keywords: Rural public health, Heart attack symptoms, Stroke symptoms, Knowledge of heart attack and stroke symptomology

\section{Background}

In the United States, the total cost(s) of cardiovascular disease (CVD) in 2010 were estimated to be $\$ 444$ billion [1]. Approximately one of every six dollars spent on health care in this country was for the treatment of CVD. Since CVD is age-prevalent, the economic impact on the U.S. health care system

\footnotetext{
* Correspondence: mlutfiyya@eirh.org

${ }^{2}$ Essentia Institute of Rural Health, Duluth, MN 55803, USA

Full list of author information is available at the end of the article
}

will become even greater as the population ages [1]. CVD encompasses numerous disease states, with heart attacks and strokes being among the most notable. For instance, in the U.S., heart disease is the number one cause of death [2] while stroke is the leading cause of long-term adult disability [3]. Therefore, early treatment for both heart attack and stroke is critical in lowering the risk for poor outcomes [4]. Understanding the signs and symptoms of heart attacks and strokes are important not only in saving lives, but also in preserving quality of life $[5,6]$.

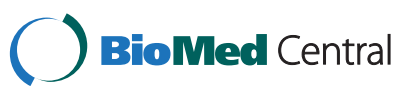


Recent research has yielded that the prevalence of cardiovascular disease risk factors are higher in rural populations [7-11] suggesting that those adults may be at higher risk for heart attack and/or stroke [12]. Knowledge of heart attack and stroke symptomology as well as calling 911 as the appropriate first response to suspected heart attack or stroke are essential first steps in seeking care [6].

A number of studies have been conducted in order to ascertain specific populations of adults with knowledge deficits in the areas of first responder action as well as heart attack and stroke symptomology. By identifying these populations of adults, better public health campaigns can be aimed at enhancing knowledge [13-21]. Despite these efforts, there has been very little research conducted to examine the knowledge level of rural U.S. populations regarding stroke and heart attack symptomology. In 2004, a small regional study encompassing the populations of two rural counties in Montana was conducted to assess the knowledge of stroke symptoms in rural adults aged 45 years and older [22]. It was found that study participants were generally aware of stroke symptomology, but not necessarily of stroke risk factors.

An epidemiological gap regarding the knowledge of heart attack and stroke symptoms among residents in rural U.S. communities is evident. This study sought to fill this knowledge gap by examining the level of understanding of heart attack and stroke symptoms among rural adults in comparison to non-rural adults living in the U.S.

\section{Methods}

Bivariate and multivariate techniques were used to analyze a multiyear Behavioral Risk Factor Surveillance Survey (BRFSS) heart attack and stroke module database. BRFSS data are collected using a random-digit dial telephone survey targeting adults 18-99 years of age. These data are collected under the guidance of the Centers for Disease Control and Prevention (CDC) in collaboration with all U.S. states and most U.S. territories. Once collected, BRFSS data are weighted such that they are representative of the non-institutional U.S. population by surveyed state. The data are cross-sectional and are focused on health risk factors and behaviors. A detailed description of the survey design and sampling measures can be found elsewhere [23].

Data from the BRFSS optional module on heart attack and stroke were used in these analyses. Because different states use this module in different years, we merged 2005, 2007, and 2009 data to include as many states and territories as possible. In 2005, 14 states, the District of Columbia and United States Virgin Islands (USVI) included a module in their BRFSS surveys regarding symptoms of heart attack and stroke. In 2007, 13 states, the District of Columbia and the USVI included the module. In 2009, it was included by 19 states and the District of Columbia. Data from 25 states, the USVI, and the District of Columbia were used in these analyses. If a state used the module more than once, only the data from the most recent year were used. For the years in question, the BRFSS heart and stroke module included 13 questions focused on ascertaining knowledge of early symptoms of heart attack and stroke. Of these 13 questions, six were on knowledge of stroke symptoms, six were on knowledge of heart attack symptoms, and one question was on proper first response to either stroke or heart attack.

Respondents were asked if the following were warning signs of stroke: sudden confusion; trouble speaking or understanding; sudden numbness or weakness of face, arm, or leg; sudden trouble seeing in one or both eyes; sudden trouble walking, dizziness, or loss of balance or coordination; or sudden, severe headache with no known cause. An incorrect sign (i.e., sudden chest pain) was included to examine the possibility that respondents would answer "yes" for all the symptoms. Likewise, respondents were asked if the following were warning signs of a heart attack: pain or discomfort in the jaw, neck, or back; feeling weak, lightheaded, or faint; chest pain or discomfort; pain or discomfort in the arms or shoulders; shortness of breath. As was the case with stroke symptoms, an incorrect sign (i.e., trouble seeing in one or both eyes) was included to examine the possibility that respondents would answer "yes" for all the symptoms.

We chose to group the questions for heart attack and stroke symptomology together for analysis because these disorders are both vascular events that require the need for prompt recognition of symptoms and pre-hospital action by either the patient or bystanders. Any costly public health campaign will likely need to address both these vascular diseases together, and strokes are often referred to as "brain attacks," as many aspects of early stroke management mimic heart attack management [24,25].

For analysis we computed a Heart Attack and Stroke Knowledge Score for each respondent. Correct answers received one point and were categorized according to the following scale: low score $0-5$ points, midrange score 6-9 points and high score $10-13$ points. Although this scale, like most, is somewhat arbitrary, we based the cut points on the actual range $(0-13)$ derived from responses. This scale served the purpose of allowing for the standardized comparison of knowledge levels.

The covariates for the analysis were: sex, age, race/ ethnicity, annual household income, education attained, marital status, geographic locale, timing of last routine medical checkup, having a personal health care provider (HCP), having health insurance, deferment of medical care because of cost, and self-defined health status. 
The Metropolitan Statistical Area (MSA) variable included in BRFSS was used to define geographic locale and was recoded into the dichotomous categories of rural or non-rural. Rural residents were defined as people living either within an MSA that had no center city or outside an MSA. Non-rural residents included all respondents living in a center city of an MSA, outside the center city of an MSA but inside the county containing the center city, or inside a suburban county of an MSA.

Race and ethnicity was also a computed variable calculated from participant responses to two separate survey questions-one regarding race and the other regarding Latino/Hispanic ethnicity. Combining the responses to these two questions allowed for the derivation of the race and ethnicity variable used in the analyses. All race/ ethnicity categories were computed as mutually exclusive entities. For example, all respondents coded as Caucasian chose White as their racial classification, likewise black for African American, etc. If a respondent identified themselves as Hispanic, they were classified by that ethnic category regardless of any additional racial classification. The category of Other/Multi-racial was also calculated. All racial categories were non-Hispanic.

A number of additional original BRFSS variables-age, education attained, marital status, and annual household income-were recoded for these analyses. Age was recoded from a continuous variable to a categorical one with three factors/levels (18-44 years, 45-64 years, and $>=65$ years). For education, marital status and household income, recoding entailed the collapsing of multiple response categories into fewer ones-three for education and two factors each for household income and marital status. The three factors for education were less than high school, at least high school, and university graduate. Annual household income was categorized into the categories of $<\$ 50,000$ and $>\$ 50,000$. Marital status was collapsed into the categories of married or living with a partner and not married or living with a partner. Three health care access variables: having a health care provider, deferment of medical care because of cost, and health insurance status were also included in these analyses. The response categories of "don't know" and "refused to answer" were recoded as missing data and removed from the analyses.

Bivariate analysis describing the three-level composite scores by each covariate was conducted as well as a description of correct and incorrect answers for each heart attack and stroke symptomology knowledge question by geographic locale (non-rural, rural and total U.S.).

Two logistic regression models were performed using low scores on the combined heart attack and stroke knowledge questions as the dependent variable. All U.S. adults were included in the first model and only rural adults $>18$ years of age responding to the survey questions were included in the second. The covariates entered into the two models were: sex, age, race/ ethnicity, education attained, marital status, annual household income, geographic locale (first model only), health status, having a personal HCP, health insurance status in the past 12 months, deferring medical care in the past 12 months because of cost, and timing of last routine medical check-up. Alpha was set at 0.05 for all tests of statistical significance. To further reduce bias, a constant was entered into the models. SPSS version 19.0 (SPSS, IBM, Chicago, IL) was used to complete the analyses to account for the complex survey design. Human subjects' approval was sought and received from Essentia Health's Institutional Review Board (IRB).

\section{Results}

From the multi-year amalgamated database complied for this study, 103,262,115 U.S. adults $>=18$ years of age

Table 1 Description of U.S. Adults Responding to Heart Attack and Stroke Symptomology Survey Questions 2005, 2007 and 2009 BRFSS Data (weighted $n=103,262,115$ )

\begin{tabular}{|c|c|c|}
\hline \multicolumn{2}{|l|}{ Covariates and Factors } & \multirow{2}{*}{$\frac{\text { Percent }}{48.6}$} \\
\hline Sex & Male & \\
\hline & Female & 51.4 \\
\hline \multirow[t]{3}{*}{$\overline{\text { Age }}$} & 18-44 Years Of Age & 49.8 \\
\hline & 45-64 Years Of Age & 33.1 \\
\hline & $>=65$ Years Of Age & 17.1 \\
\hline \multirow[t]{4}{*}{ Race And Ethnicity } & Caucasian & 72.0 \\
\hline & African American & 10.9 \\
\hline & Hispanic & 10.2 \\
\hline & Other/Multiracial & 6.9 \\
\hline \multirow[t]{3}{*}{ Education Attained } & Did Not Graduate From HS & 10.9 \\
\hline & HS Graduate & 56.3 \\
\hline & University Graduate & 32.8 \\
\hline \multirow[t]{2}{*}{ Marital Status } & Married Or Living With Partner & 64.1 \\
\hline & Not Married Or Living With Partner & 35.9 \\
\hline \multirow{2}{*}{$\begin{array}{l}\text { Annual Household } \\
\text { Income }\end{array}$} & $<\$ 50,000$ & 53.1 \\
\hline & $>=\$ 50,000$ & 46.9 \\
\hline \multirow[t]{2}{*}{ Geographic Locale } & Non-Rural & 78.1 \\
\hline & Rural & 21.9 \\
\hline \multirow[t]{2}{*}{ Health Status } & Good To Excellent Health & 83.9 \\
\hline & Fair To Poor Health & 16.1 \\
\hline \multirow[t]{2}{*}{ Health Insurance Status } & Have Health Insurance & 85.2 \\
\hline & Do Not Have Health Insurance & 14.8 \\
\hline \multirow{2}{*}{$\begin{array}{l}\text { Have Health Care } \\
\text { Provider }\end{array}$} & Have HCP & 80.8 \\
\hline & Do Not Have HCP & 19.2 \\
\hline \multirow[t]{2}{*}{$\begin{array}{l}\text { Deferment of Medical } \\
\text { Care }\end{array}$} & $\begin{array}{l}\text { Medical Care Deferred } \\
\text { Because of Cost }\end{array}$ & 13.8 \\
\hline & Medical Care Not Deferred & 86.2 \\
\hline \multirow{2}{*}{$\begin{array}{l}\text { Timing of Routine } \\
\text { Medical Check Up }\end{array}$} & Within Last 12 Months & 67.3 \\
\hline & Longer Than 12 Months Ago & 32.7 \\
\hline
\end{tabular}


from 25 states, the USVI and the District of Columbia responded to the optional heart attack and stroke symptom module. Approximately $22.0 \%$ of these respondents were U.S. adults living in rural locales. Table 1 describes the population responding to the heart attack and stroke symptom module questions in 2005, 2007 and 2009.

Table 2 displays the bivariate analysis of the composite heart attack and stroke three-level knowledge score by the study covariates. Notably this analysis yielded that higher percentages of males as well as those adults defining their health as fair to poor, without health insurance, without a personal HCP, deferring medical care because of cost, having their last routine medical check-up longer than 12 months ago, living in households with an annual income of $<\$ 50,000$, who are Hispanic, and living in rural locales had a low composite heart attack and stroke symptom knowledge score. This analysis also revealed that not having graduated from high school was a strong bivariate predictor of having a low composite heart attack and stroke symptomology knowledge score.

A bivariate analysis of the percent correct and incorrect responses by symptom question and geographic locale of respondents (non-rural, rural and total U.S.) is displayed in Table 3. For nine of the 13 questions (69.3\%) on heart attack and stroke symptomology (three heart attack questions, four stroke questions, and appropriate first response question), rural respondents had higher percentages of incorrect answers.

Table 4 displays the results of the two logistic regression models performed. The first logistic regression analysis using low composite heart attack and stroke symptom knowledge score as the dependent variable revealed that those US adults who had low composite heart attack and stroke knowledge scores were more likely to be rural $(\mathrm{OR}=1.21895 \% \mathrm{CI} 1.216-1.219)$ rather than non-rural residents. Furthermore, those with low scores were more likely to be: male $(\mathrm{OR}=1.35395 \% \mathrm{CI}$ $1.352-1.354),>65$ years of age $(\mathrm{OR}=1.36995 \% \mathrm{CI} 1.368$ 1.371), African American ( $\mathrm{OR}=1.892$ 95\%CI 1.8891.894), not educated beyond high school $(\mathrm{OR}=1.400$ 955CI 1.399-1.402), uninsured (OR $=1.308$ 95\%CI 1.3-61.310), without a $\mathrm{HCP}(\mathrm{OR}=1.21695 \% \mathrm{CI} 1.215-1.218)$, and living in a household with $<\$ 50,000$ annual income $(\mathrm{OR}=1.429$ 95\% CI 1.428-1.431).

Table 2 Composite Heart Attack and Stroke Symptomology Knowledge Score By Covariates 2005, 2007 and 2009 BRFSS Data

\begin{tabular}{|c|c|c|c|c|}
\hline \multirow[t]{2}{*}{ Covariates and Factors } & & \multicolumn{3}{|c|}{ Three Level Composite Score } \\
\hline & & $\begin{array}{l}\text { \% Low Composite } \\
\text { Score* }\end{array}$ & $\begin{array}{l}\text { \% Mid-Range Composite } \\
\text { Score* }\end{array}$ & $\begin{array}{l}\% \text { High Composite } \\
\text { Score* }\end{array}$ \\
\hline \multirow[t]{2}{*}{ Sex } & Male & 8.6 & 36.9 & 54.5 \\
\hline & Female & 6.3 & 31.7 & 62.0 \\
\hline \multirow[t]{2}{*}{ Health Status } & Good To Excellent Health & 6.6 & 33.4 & 60.0 \\
\hline & Fair To Poor Health & 11.2 & 38.4 & 50.5 \\
\hline \multirow[t]{2}{*}{ Health Insurance Status } & Have Health Insurance & 6.3 & 32.6 & 61.1 \\
\hline & Do Not Have Health Insurance & 13.1 & 42.7 & 44.1 \\
\hline \multirow[t]{2}{*}{ Have Health Care Provider } & Have HCP & 6.3 & 32.6 & 61.0 \\
\hline & Do Not Have HCP & 11.6 & 40.8 & 47.7 \\
\hline \multirow[t]{2}{*}{ Medical Care Deferred } & Deferred Because Of Cost & 9.6 & 39.5 & 50.9 \\
\hline & Care Not Deferred & 6.9 & 33.3 & 59.8 \\
\hline \multirow[t]{2}{*}{ Routine Medical Check Up } & Within Last 12 Months & 7.1 & 33.0 & 59.9 \\
\hline & Longer Than 12 Months Ago & 8.0 & 37.0 & 55.0 \\
\hline \multirow[t]{3}{*}{ Education Attained } & Did Not Graduate From HS & 20.9 & 46.1 & 33.0 \\
\hline & HS Graduate & 7.2 & 36.6 & 56.2 \\
\hline & University Graduate & 3.3 & 26.4 & 70.3 \\
\hline \multirow[t]{2}{*}{ Household Income } & $<\$ 50,000$ & 9.6 & 38.7 & 51.7 \\
\hline & $>=\$ 50,000$ & 3.1 & 27.4 & 69.5 \\
\hline \multirow[t]{4}{*}{ Race And Ethnicity } & Caucasian & 5.0 & 31.5 & 63.5 \\
\hline & African American & 12.4 & 42.7 & 44.9 \\
\hline & Hispanic & 20.7 & 43.7 & 35.6 \\
\hline & Other/Multiracial & 10.7 & 39.5 & 49.8 \\
\hline \multirow[t]{2}{*}{ Geographic Locale } & Non-Rural & 7.3 & 34.2 & 58.6 \\
\hline & Rural & 7.7 & 34.5 & 57.8 \\
\hline
\end{tabular}

*By z-statistic column proportions differ significantly from each other at the .05 level. 
Table 3 Heart Attack and Stroke Symptomology Knowledge Questions With\% Incorrect and Correct Responses U.S. Adults by Geographic Locale 2005, 2007 and 2009 behavioral risk factor surveillance data

\begin{tabular}{|c|c|c|c|c|}
\hline \multirow[t]{2}{*}{ Survey Question (Correct Response) } & & \multicolumn{2}{|c|}{ Geographic Locale } & \multirow[b]{2}{*}{ Total U.S } \\
\hline & & Non-Rural & Rural & \\
\hline \multirow{2}{*}{$\begin{array}{l}\text { Do you think pain or discomfort in the jaw, neck, or back } \\
\text { are symptoms of a heart attack? (Yes) }\end{array}$} & Incorrect Answer & 46.6 & 44.2 & 46.0 \\
\hline & Correct Answer & 53.4 & 55.8 & 54.0 \\
\hline \multirow{2}{*}{$\begin{array}{l}\text { Do you think feeling weak, lightheaded, or faint are } \\
\text { symptoms of a heart attack? (Yes) }\end{array}$} & Incorrect Answer & 36.7 & 37.2 & 36.8 \\
\hline & Correct Answer & 63.3 & 62.8 & 63.2 \\
\hline \multirow{2}{*}{$\begin{array}{l}\text { Do you think chest pain or discomfort are symptoms for a } \\
\text { heart attack? (Yes) }\end{array}$} & Incorrect Answer & 7.2 & 7.7 & 7.3 \\
\hline & Correct Answer & 92.8 & 92.3 & 92.7 \\
\hline \multirow{2}{*}{$\begin{array}{l}\text { Do you think sudden trouble seeing in one or both eyes is } \\
\text { a symptom of a heart attack? (No) }\end{array}$} & Incorrect Answer & 57.3 & 59.2 & 57.8 \\
\hline & Correct Answer & 42.7 & 40.8 & 42.2 \\
\hline \multirow{2}{*}{$\begin{array}{l}\text { Do you think pain or discomfort in the arms or shoulders } \\
\text { are symptoms of a heart attack? (Yes) }\end{array}$} & Incorrect Answer & 13.5 & 13.5 & 13.5 \\
\hline & Correct Answer & 86.5 & 86.5 & 86.5 \\
\hline \multirow{2}{*}{$\begin{array}{l}\text { Do you think shortness of breath is a symptom of a heart } \\
\text { attack? (Yes) }\end{array}$} & Incorrect Answer & 15.1 & 15.0 & 15.1 \\
\hline & Correct Answer & 84.9 & 85.0 & 84.9 \\
\hline \multirow{2}{*}{$\begin{array}{l}\text { Do you think sudden confusion or trouble speaking are } \\
\text { symptoms of a stroke? (Yes) }\end{array}$} & Incorrect Answer & 10.2 & 10.7 & 10.3 \\
\hline & Correct Answer & 89.8 & 89.3 & 89.7 \\
\hline \multirow{2}{*}{$\begin{array}{l}\text { Do you think sudden numbness or weakness of face, arm, or } \\
\text { leg, especially on one side are symptoms of a stroke? (Yes) }\end{array}$} & Incorrect Answer & 6.1 & 6.3 & 6.2 \\
\hline & Correct Answer & 93.9 & 93.7 & 93.8 \\
\hline \multirow{2}{*}{$\begin{array}{l}\text { Do you think sudden trouble seeing in one or both eyes is } \\
\text { a symptom of a stroke? (Yes) }\end{array}$} & Incorrect Answer & 27.6 & 29.7 & 28.1 \\
\hline & Correct Answer & 72.4 & 70.3 & 71.9 \\
\hline \multirow{2}{*}{$\begin{array}{l}\text { Do you think sudden chest pain or discomfort are } \\
\text { symptoms of a stroke? (No) }\end{array}$} & Incorrect Answer & 58.7 & 62.6 & 59.7 \\
\hline & Correct Answer & 41.3 & 37.4 & 40.3 \\
\hline \multirow{2}{*}{$\begin{array}{l}\text { Do you think sudden trouble walking, dizziness, or loss of } \\
\text { balance are symptoms of a stroke? (Yes) }\end{array}$} & Incorrect Answer & 14.3 & 15.2 & 14.6 \\
\hline & Correct Answer & 85.7 & 84.8 & 85.4 \\
\hline \multirow{2}{*}{$\begin{array}{l}\text { Do you think severe headache with no known cause is a } \\
\text { symptom of a stroke? (Yes) }\end{array}$} & Incorrect Answer & 39.1 & 38.4 & 38.9 \\
\hline & Correct Answer & 60.9 & 61.6 & 61.1 \\
\hline \multirow{2}{*}{$\begin{array}{l}\text { If you thought someone was having a heart attack or a } \\
\text { stroke, what is the first thing you would do? (call 911) }\end{array}$} & Incorrect Answer & 12.1 & 16.1 & 13.1 \\
\hline & Correct Answer & 87.9 & 83.9 & 86.9 \\
\hline
\end{tabular}

The second logistic regression model also using low composite heart attack and stroke symptom knowledge score as the dependent variable and including only rural U.S. adults yielded similar results, many of which were magnified for rural Americans. Specifically, U.S. rural adults with low composite heart attack and stroke symptom knowledge scores were more likely to be male, $>65$ years of age, Hispanic and/or other/Multiracial, less educated (not a high school graduate or just a high school graduate), not married or living with a partner, living in a household with $<\$ 50,000$ as an annual income, not have health insurance, not have a personal HCP, and have had a routine medical check-up longer than 12 months ago.

\section{Discussion}

Our results suggest that U.S. adults living in rural locales have a knowledge deficit regarding heart attack and stroke symptomology as well as appropriate first response to heart attack and/or stroke. As with other research conducted on heart attack and stroke symptom knowledge in multiple groups (e.g., African American women, Hispanic males, African American men) [18-21], not all rural adults are likely to score low on knowledge questions about heart attack and stroke signs and symptoms. Our study identified the characteristics of rural adults who were more likely to do so. We found that rural adults who did not graduate from high school, those who were economically poorer or male or Hispanic were more likely to be low scorers regarding correct answers on heart attack and stroke symptomology questions.

For rural residents, knowing the signs and symptoms of heart attack and stoke is imperative given the importance of time from the onset of the event to appropriate treatment because of added distance to the hospital. While knowledge alone may be insufficient to spur action, it is the first step [26]. As such, tailored public health campaigns are essential for U.S. rural adults to enhance knowledge regarding heart attack and stroke symptomology. 
Table 4 Logistic Regression Model of Low Composite Heart Attack and Stroke Knowledge Scorers 2005, 2007 and 2009 Amalgamated BRFSS Database

\begin{tabular}{|c|c|c|c|}
\hline \multirow[t]{2}{*}{ Covariate } & \multirow[t]{2}{*}{ Factor } & \multicolumn{2}{|c|}{ Geographic Locale } \\
\hline & & $\begin{array}{l}\text { US Total Adjusted Odds } \\
\text { Ratio }(95 \% \mathrm{CI})\end{array}$ & $\begin{array}{l}\text { Rural Adjusted Odds } \\
\quad \text { Ratio }(95 \% \mathrm{Cl})\end{array}$ \\
\hline \multirow[t]{2}{*}{ Sex } & Male & $1.353(1.352,1.354)$ & $1.457(1.454,1.459)$ \\
\hline & Female & $-{ }^{*}$ & $-^{*}$ \\
\hline \multirow[t]{3}{*}{ Age } & $18-44$ years of age & $-{ }^{*}$ & $-^{*}$ \\
\hline & 45-64 years of age & $.811(.810, .812)$ & $.771(.770, .773)$ \\
\hline & $>65$ years of age & $1.369(1.368,1.371)$ & $1.269(1.265,1.272)$ \\
\hline \multirow[t]{4}{*}{ Race and Ethnicity } & Caucasian & $-{ }^{*}$ & $-^{*}$ \\
\hline & African American & $1.892(1.889,1.894)$ & $1.763(1.758,1.768)$ \\
\hline & Hispanic & $.821(.819, .822)$ & $2.787(2.772,2.802)$ \\
\hline & Other/Multiracial & $1.041(1.039,1.043)$ & $1.487(1.481,1.493)$ \\
\hline \multirow[t]{3}{*}{ Education Attained } & Did Not Graduate From High School & $2.021(2.018,2.024)$ & $3.177(3.166,3.188)$ \\
\hline & High School Graduate & $1.400(1.399,1.402)$ & $1.688(1.684,1.692)$ \\
\hline & University Graduate & $-{ }^{*}$ & $-^{*}$ \\
\hline \multirow[t]{2}{*}{ Marital Status } & Married Or Living With Partner & $--^{*}$ & $--^{*}$ \\
\hline & Not Married Or Living With Partner & $1.080(1.079,1.082)$ & $1.149(1.147,1.152)$ \\
\hline \multirow[t]{2}{*}{ Annual Household Income } & $<\$ 50,000$ & $1.429(1.428,1.431)$ & $1.438(1.434,1.441)$ \\
\hline & $>\$ 50,000$ & $-^{*}$ & $-{ }^{*}$ \\
\hline \multirow[t]{2}{*}{ Geographic Locale } & Non-Rural & $-{ }^{*}$ & \\
\hline & Rural & $1.218(1.216,1.219)$ & \\
\hline \multirow[t]{2}{*}{ Health Status } & Good To Excellent Health & $-{ }^{*}$ & $-{ }^{*}$ \\
\hline & Fair To Poor Health & $1.063(1.061,1.064)$ & $1.056(1.054,1.059)$ \\
\hline \multirow[t]{2}{*}{ Health Insurance Status } & Have Health Insurance & $--^{*}$ & $-{ }^{*}$ \\
\hline & Do Not Have Health Insurance & $1.308(1.306,1.310)$ & $1.174(1.170,1.177)$ \\
\hline \multirow[t]{2}{*}{ Health Care Provider } & Have HCP & $-{ }^{*}$ & $-^{*}$ \\
\hline & Do Not Have HCP & $1.216(1.215,1.218)$ & $1.146(1.143,1.149)$ \\
\hline \multirow[t]{2}{*}{ Deferment of Medical Care } & Medical Care Deferred Because Of Cost & $1.136(1.135,1.138)$ & $.903(.901, .906)$ \\
\hline & Medical Care Not Deferred & $-^{*}$ & $-{ }^{*}$ \\
\hline \multirow{2}{*}{$\begin{array}{l}\text { Timing of Routine Medical } \\
\text { Check Up }\end{array}$} & Within Last 12 Months & $-^{*}$ & $-^{*}$ \\
\hline & Longer Than 12 Months Ago & $.992(.991, .993)$ & $1.125(1.122,1.127)$ \\
\hline
\end{tabular}

*Referent Category.

We believe that pharmacists can and should play a role-perhaps even taking the lead-in helping to educate rural U.S. adults about the symptoms of heart attack and stroke. Community pharmacists, especially in rural communities, are easily accessible health care providers $[26,27]$. They may be the only health care providers in many rural communities. Pharmacist-driven public health related interventions have been successful in multiple communities for a variety of health concerns (e.g., smoking, hypertension, hyperlipidemia, elevated blood glucose) [28-32].

From the practice setting of a community pharmacy, pharmacists' could mount low-cost campaigns to inform their rural patients about the signs and symptoms of heart attack and stroke. Elements of such a campaign may include: posters, medication counseling, pamphlets and community outreach programs. Furthermore, hospital- based pharmacists could partner with critical access hospitals to provided community outreach programs that not only provide education on the symptomology of strokes and heart attacks but also providing information of how to access care if and or when it might be needed. Finally, from the practice setting of primary care clinics, pharmacists could identify high-risk patients by using medical records and provide education during clinic visits. They might also offer group visits for high risk patients in order to provide additional education regarding CVD and heart attack and stroke signs and symptoms.

\section{Study limitations}

Several potential limitations to this study should be noted. First, the survey is based on telephone derived data and may be skewed because those who could not be reached by phone could not participate in the survey. Additionally, 
widespread use of answering machines and caller identification now allow people to filter their phone calls potentially leading to a passive refusal to participate in surveys such as the BRFSS. However, call filtering is beyond the control of survey administrators. Furthermore, persons of lower socioeconomic status may have been excluded because of poorer phone access. However, the vast majority of U.S. residents live in households with telephones, which minimizes this bias. Moreover, U.S. cell phone numbers are now included in the pool of phones contacted for the survey. Nevertheless, study strength is in the use of a national database that included a robust sample of residents weighted to reflect the demographics of the U.S. population.

A second limitation is that the survey used close-ended questions, which limit participants' options to fully explain response choices. Nonetheless, the survey questions were worded such that the answer choices covered a wide range of response possibilities. A third, and related, limitation is that the answers are self-reported, which introduces the possibility of recall bias on the part of the survey participants. A final potential bias resulted from the languages of the survey - English and Spanish. Individuals who did not speak English or Spanish were excluded from this survey.

\section{Conclusions}

Analyses identified clear disparities between the knowledge levels of rural in comparison to non-rural U.S. adults regarding heart attack and stroke symptoms as well as appropriate first response to either event. These disparities should inform educational endeavors focused on improving knowledge of heart attack and stroke symptoms. Since pharmacists provide health care in multiple settings, they may be the best situated health care providers to take the lead in such public health education efforts.

\section{Competing interests}

The authors declare that they have no competing interests.

\section{Acknowledgements}

No acknowledgements. There was no external funding for this research study.

\section{Author details}

'College of Pharmacy, Ambulatory Care Residency Program, University of Minnesota, Minneapolis, MN 55455, USA. ${ }^{2}$ Essentia Institute of Rural Health, Duluth, MN 55803, USA. ${ }^{3}$ Essentia Health System, Ambulatory Care Pharmacy Services, Duluth, MN 55805, USA.

\section{Authors' contributions}

MTS, MNL, MLA, MFA, KLH all made substantial contributions to conception and design of the manuscript, contributed to the interpretation of the data, were involved in revising the manuscript critically for important intellectual content, and have given final approval of this version of the manuscript to be published. Additionally, MNL oversaw: the completion of the first draft of the manuscript, the acquisition of the data and the statistical analyses. All authors read and approved the final manuscript.

Received: 30 December 2011 Accepted: 10 April 2012

Published: 10 April 2012

\section{References}

1. Heidenreich PA, Trogdon JG, Khavjou OA, Butler J, Dracup K, Ezekowitz MD, Finkelstein EA, Hong Y, Johnston SC, Khera A, Lloyd-Jones DM, Nelson SA, Nichol G, Orenstein D, Wilson PWF, Woo YJ: Forecasting the future of cardiovascular disease in the United States: a policy statement from the American Heart Association. Circulation 2011, 123:933-944.

2. Miniño AM: Death in the United States, 2009. In NCHS data brief, no 64. Hyattsville, MD: National Center for Health Statistics; 2011.

3. Petrea RE, Beiser AS, Seshadri S, Kelly-Hayes M, Kase CS, Wolf PA: Gender differences in stroke incidence and poststroke disability in the framingham heart study. Stroke 2009, 40:1032-1037.

4. Moser DK, Kimble LP, Alberts MJ, Alonzo A, Croft JB, Dracup K, Evenson KR, Go AS, Hand MM, Kothari RU, Mensah GA, Morris DL, Pancioli AM, Riegel B, Zerwic JJ: Reducing delay in seeking treatment by patients with acute coronary syndrome and stroke a scientific statement from the American heart association council on cardiovascular nursing and stroke council. Circulation 2006, 114:168-182

5. Turner GO, Rosin MB: Recognizing and surviving heart attacks and strokes: lifesaving advice you need now. Columbia, Missouri: University of Missouri Press; 2008.

6. Wall HK, Beagan BM, O'Neill HJ, Foell KM, Boddie-Willis CL: Addressing Stroke Signs and Symptoms Through Public Education: The Stroke Heroes Act FAST Campaign. Prev Chronic Dis 2008, 5.

7. Doescher MP, Jackson JE, Jerant A, Hart LG: Prevalence and Trends in Smoking: A National Rural Study. J Rural Health 2006, 2:112-118.

8. Danaei G, Rimm EB, Oza S, Kulkarni SC, Murray CJL, Ezzati M: The Promise of Prevention: The Effects of Four Preventable Risk Factors on National Life Expectancy and Life Expectancy Disparities by Race and County in the United States. PLoS Medicine 2010, 7.

9. Vander Weg MW, Cunningham CL, Howren MB, Cai X: Tobacco use and exposure in rural areas: findings from the behavioral risk factor surveillance system. Addict Behav 2011, 36:231-236.

10. Lutfiyya MN, Shah KK, Johnson M, Bales RW, Cha I, McGrath C, Serpa L, Lipsky MS: Adolescent daily cigarette smoking: is rural residency a risk factor? Rural Remote Health 2008, 8:875.

11. Krishna S, Gillespie KN, McBride TM: Diabetes burden and access to preventive care in the rural United States. J Rural Health 2010, 26:3-11.

12. Pedigo A, Seaver $W$, Odoi A: Identifying unique neighborhood characteristics to guide health planning for stroke and heart attack: fuzzy cluster and discriminant analyses approaches. PLOS ONE 2011, 6.

13. Greenlund KJ, Keenan NL, Giles WH, Zheng ZJ, Neff LJ, Croft JB, Mensah GA: Public recognition of major signs and symptoms of heart attack: seventeen states and the US Virgin Islands, 2001. Am Heart J 2004, 147:1010-1016.

14. Chow CM, Chu JY, Tu JV, Moe GW: Lack of awareness of heart disease and stroke among Chinese Canadians: results of a pilot study of the Chinese Canadian Cardiovascular Health Project. Can J Cardiol 2008, 24:623-628.

15. Brega AG, Noe T, Loudhawk-Hedgepeth C, Jim DM, Morse B, Moore K, Manson SM: Cardiovascular knowledge among urban American Indians and Alaska natives: first steps in addressing cardiovascular health. Prog Community Health Partnersh 2011, 5:273-279.

16. Margellos-Anast H, Estarziau M, Kaufman G: Cardiovascular disease knowledge among culturally Deaf patients in Chicago. Prev Med 2006, 42:235-239.

17. Tullmann DF, Dracup K: Knowledge of heart attack symptoms in older men and women at risk for acute myocardial infarction. $J$ Cardiopulm Rehabil 2005, 25:33-39.

18. Lutfiyya MN, Bardales R, Bales R, Aguero C, Brady S, Tobar A, McGrath C, Zaiser J, Lipsky MS: Awareness of heart attack and stroke symptoms among Hispanic male adults living in the United States. I Immigr Minor Health 2010, 12:761-768.

19. Lutfiyya MN, Ng L, Asner N, Lipsky MS: Disparities in stroke symptomology knowledge among US midlife women: an analysis of population survey data. J Stroke Cerebrovasc Dis 2009, 18:150-157.

20. Lutfiyya MN, Lipsky MS, Bales RW, Cha I, McGrath C: Disparities in knowledge of heart attack and stroke symptoms among adult men: an analysis of behavioral risk factor surveillance survey data. J Natl Med Assoc 2008, 100:1116-11124.

21. Lutfiyya MN, Cumba MT, McCullough JE, Barlow EL, Lipsky MS: Disparities in adult African American women's knowledge of heart attack and stroke symptomatology: an analysis of 2003-2005 behavioral risk factor surveillance survey data. J Womens Health 2008, 17:805-813. 
22. Harwell TS, Blades LL, Oser CS, Fogle CC, Helgerson S, Gohdes D, Dietrich DW, Burnett AM, Okon NJ, Allen MJ, Rodriguez DV, Russell JA: Rural community knowledge of stroke warning signs and risk factors. Prev Chronic Dis 2005, 2:A14.

23. Mokdad AH, Stroup DF, Giles WH: Public health surveillance for behavioral risk factors in a changing environment: recommendations from the Behavioral Risk Factor Surveillance Team. Morb Mortal Wkly 2003, 52:RR09.

24. Camarata PJ, Heros RC, Latchaw RE: "Brain attack": the rationale for treating stroke as a medical emergency. Neurosurgery 1994, 34:144-157.

25. Chaturvedi S: Should stroke be considered both a brain attack and a heart attack? Stroke 2007, 38:1713-1714.

26. Al Hamarneh YN, Crealey GE, MCElnay JC: Coronary heart disease: health knowledge and behavior. Int J Clin Pharm 2011, 33:111-123.

27. Goode KR: Change in community pharmacy practice-it is not just coming from the cash register. U S Pharm Rev 2006.

28. Maguire TA, McElnay JC, Drummond A: A randomized controlled trial of a smoking cessation intervention based in community pharmacies. Addiction 2001, 96:325-331.

29. Tsuyuki RT, Johnson JA, Teo KK, Simpson SH, Ackman ML, Biggs RS, Cave A, Chang WC, Dzavik V, Farris KB, Galvin D, Semchuk W, Taylor JG: A randomized trial of the effect of community pharmacist intervention on cholesterol risk management: the study of cardiovascular risk intervention by pharmacists (SCRIP). Arch Intern Med 2002, 162:1149-1155.

30. Zillich AJ, Sutherland JM, Kumbera PA, Carter BL: Hypertension outcomes through blood pressure monitoring and evaluation by pharmacists (HOME study). JGIM 2005, 20:1091-1096.

31. McLean DL, McAlister FA, Johnson JA, King KM, Makowsky MJ, Jones CA, Tsuyuki RT: A randomized trial of the effect of community pharmacist and nurse care on improving blood pressure management in patients with diabetes mellitus: study of cardiovascular risk intervention by pharmacistshypertension (SCRIPHTN). Arch Intern Med 2008, 168:2355-2361.

32. Sinclair HK, Bond CM, Lennox AS, Silcock J, Winfield A: Knowledge of and attitudes to smoking cessation: the effect of stage of change training for community pharmacy staff. Health Bull 1998, 56:526-539.

doi:10.1186/1471-2458-12-283

Cite this article as: Swanoski et al.: Knowledge of heart attack and stroke symptomology: a cross-sectional comparison of rural and non-rural US adults. BMC Public Health 2012 12:283.

\section{Submit your next manuscript to BioMed Central and take full advantage of:}

- Convenient online submission

- Thorough peer review

- No space constraints or color figure charges

- Immediate publication on acceptance

- Inclusion in PubMed, CAS, Scopus and Google Scholar

- Research which is freely available for redistribution 